\title{
Risk management project for work with precast concrete shells
}

\author{
Linda Rose ${ }^{\text {a }}$ \\ ${ }^{a}$ Department of Ergonomics, School of Technology and Health, KTH, The Royal Institute of Technology, Alfred \\ Nobels Allé 10, 14152 Huddinge, Sweden
}

\begin{abstract}
This paper describes a project with the aim of reducing the risk of injury when using precast concrete shells in the Swedish construction industry by identifying injury risks, developing and implementing solutions. An interactive research approach was used. Three major injury risks were identified and a system consisting of three tools and a handbook was developed, evaluated, and implemented at one company and made available to the construction industry.
\end{abstract}

Keywords: construction industry, development, tool, handbook, methods

\section{Introduction}

The use of precast concrete elements is becoming more common at construction sites. While they offer several ergonomic advantages, there is also potential for new personal injury risks.

The overall aim of this project was to reduce the injury risks when using precast concrete shells, which often weigh up to $6000 \mathrm{~kg}$. To achieve this, specific objectives were to 1 ) Identify and assess the major work-related personal injury risks when using precast concrete shells, 2) Develop ideas to reduce the risks, 3) Develop, test, and evaluate tools which reduce risk, 4) Develop, test and evaluate a handbook to handle the precast elements, 5) Implement a system consisting of both tools and handbook and 6) Disseminate the results to the Swedish construction industry.

\section{Methods and project process}

In this project, an Interactive Research approach was used. This is characterized by relationships among equals where researchers and participants at companies work together with a high degree of participation to reach practically relevant goals that are of a high scientific standard [1].

The project was conducted in two phases: the first addressed objectives 1 and 2 above; the second ad- dressed the remaining objectives. Seven companies active in the Swedish construction industry participated with managers and construction workers. The project was mainly funded by financial support from SBUF, the Swedish construction industry's organization for research and development. Suggestions for solutions to reduce the risks were developed in close co-operation between the researcher and the industry. A reference group was linked to the project. This group included representatives from participating construction companies and concrete factories, researchers and parties associated with the labour market. The reference group formed a platform for discussion, knowledge transfer and advice in a broader network, giving valuable input into the project and highlighted needs of different stakeholders.

As part of the risk identification a literature review was carried out. Risk management procedures involved implementation of the Statistically-based Cost Analysis Method (SCA) and the Method for Analysing Work-related Risks, Improving Work Environment and Estimating Total Cost (MAWRIC) [2]. SCA gives an overview of the injury risks and the costs caused by poor working environment at company or work place level. Input data can be taken from official trade or in-house statistics on injuries (frequency, sick-leave duration, et cetera). Hidden costs from reduced productivity and quality, administration and overtime are accounted for by a fixed mark-up. Productivity losses due to reduced working ability and costs for rehabilitation are also taken into 
consideration. MAWRIC can be used for risk management and for calculating the costs of work-related personal injuries for work tasks. The analysis is carried out with a six-step process including: risk identification, risk assessment, development of risk reducing measures, estimation of the costs and benefits associated, and follow-up after implementation. Risks are determined from estimated probabilities and consequences by using a risk matrix approach.

Development of risk-reducing ideas and Product development was conducted using an interactive and participative methodology derived from Andersson's System Group methodology [3]. An idea-seminar was used to generate solution-ideas. These were initially evaluated with respect to their feasibility of becoming a real product and subsequently, based on three criteria: ergonomics and safety, economic effects at the company level, and quality of the resulting work. Spider diagrams [4] were used to summarize the evaluations. The ideas assessed to have best potential according to the criteria and to make it to the market were developed further. The ideas considered most favourable for success were selected in an 'evaluation-seminar'.

In phase two, the product development, the tests and the evaluation was done in close co-operation with the users, i.e. the construction workers working with precast concrete elements. Prototypes of solutions were developed, tested at construction sites and modified to improve usability and safety.

The prototypes were tested by and discussed with the construction workers and thereafter modified at several stages. Subsequently the prototypes were evaluated at construction sites by both construction workers and the project group. The risks were assessed in co-operation with designers, construction workers and the managements of the companies involved. For the evaluation of the injury risks, the user friendliness and ergonomics semi-structured interviews and specially designed questionnaires were used, as well as Borg's RPE-scale [5] and parts of the Standardised Nordic Questionnaires [6]. The quality of work was studied by inspection in co-operation with the manager at one company, who also participated in an economic evaluation. Work with the prototypes was also photo- and video- documented.

Furthermore, a handbook of how to work with precast elements was developed to inform about risks and how to reduce them. This was also done in close co-operation with construction workers and the industry. A draft was developed and distributed to the people involved. It was modified three times until it had the final content and form. At this phase an eco- nomic evaluation of the system was carried out where the direct cost for the equipment and material was complemented with calculations of the costs for work related personal injuries.

\section{Results}

\subsection{Injury risks}

Based on the literature review and the analysis using SCA and MAWRIC three major injury risks were identified: 1) Squeezing or crushing of hands, 2) Falling to the ground and 3) Accidents from ladders.

The risk for squeezing accidents, especially on hands and feet, was assessed as serious. It arises when transporting the shells from the truck with a crane to the place of assembly. Most accidents when working with concrete elements occur during material handling [7]. In Sweden, 164 work accidents were reported in 1997-2000 where the main factor causing the accident was larger concrete elements, wall elements or concrete beams [8].

Figure 1 illustrates one common design of precast concrete shells for applications with high structural strength requirements. It is tempting to use the bended reinforcement parts as handles when guiding the shell to the right place which results in high squeezing risk. In the project several construction workers stated that they had been very close to squeeze their hands while directing and fitting the shells into place. 
Fig. 1: Example of design of precast element with projecting reinforcement from the shell, often used as handles when directing and fitting the elements into place.

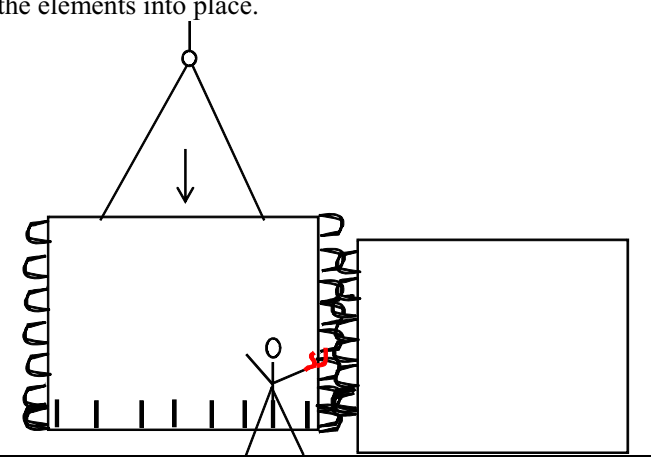

The risk of falling from the precast walls e.g. during casting when no floor structure exists was also assessed to be serious. For such work a scaffold should be built or some kind of safety device should be used before casting, but this is not always done. The reasons may be feeling lack of time or space or that the actual building of the safety equipment or scaffold is considered difficult. Falling off a structure is still the predominant cause of accident amongst construction workers in Sweden [9].

The third risk, falling from ladders, occurs mainly when the ladder slides on the ground. When the ground is uneven the risk increases.

\subsection{Developing ideas for solutions}

The idea-seminar resulted in about 40 ideas. These were evaluated as described under Methods. Ten of these ideas were looked into more deeply, therefore resulting in a further study, and were evaluated at the Evaluation seminar. At this stage a system consisting of three tools and a handbook were suggested for development.

\subsection{Prototype development and test}

The prototypes of the three tools and the handbook were all developed in a participative and iterative process in close co-operation with the participating companies, mainly with the construction company initiating the project and the concrete factory within the same group of companies.

\subsubsection{A handle to prevent squeezing hands}

The Conny-handle, named after the construction worker who came up with the idea, was developed for workers to position the precast shells, rather than directly gripping the edge of the shell or its rein- forcement, see Figure 2. It is easy to adjust to the thickness of the concrete shell thickness and also easy to fasten and detach, yet gives a good grip while attached.

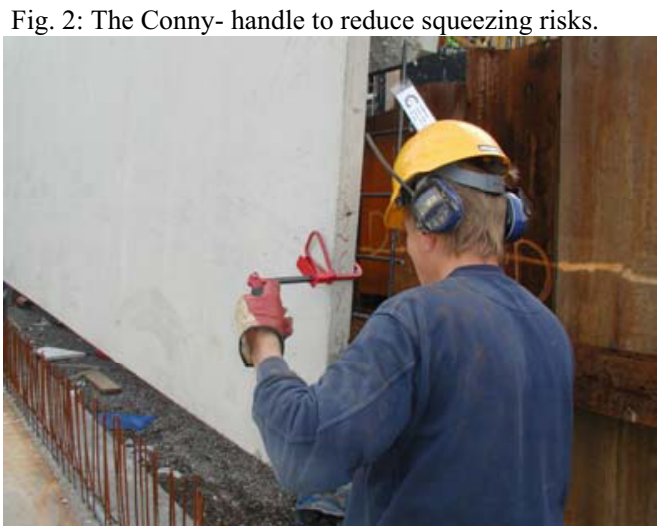

\subsubsection{Preventing falls with a work platform}

A clamp, named the APJ-clamp, was developed to attach existing work platforms to the concrete shells to prevent falling accidents when working from them. The clamps are hung on the precast shell, and the standard safety equipment is then fastened on the clamps, see Figure 3

Fig. 3: The APJ-clamp as part of a work platform for preventing falls.

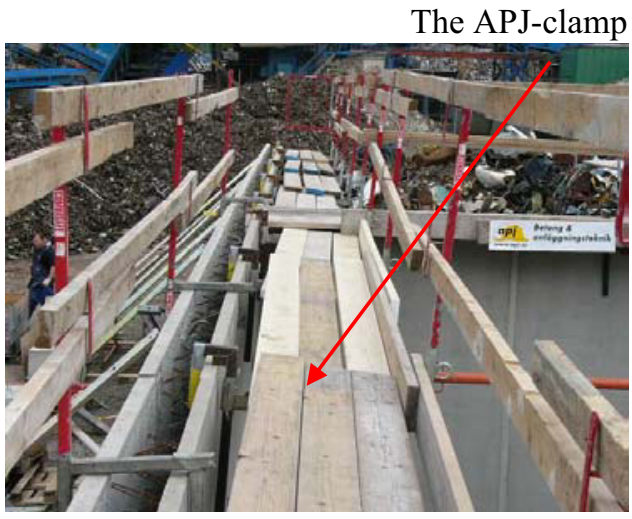

\subsubsection{Preventing accidents from ladders}

To ease the work and reduce the risk of the ladder slipping away and thereby causing a falling accident, while moving up or down on the ladder, a ladder that is hung on the precast shell and does not reach the ground was developed. It "locks" during loading, and as a result does not slip. The "novelty" is made up of two parts that can be attached to a traditional ladder, see Figure 4. One part enables the hanging on the shells upper edge, the other guarantees a distance to the shell. 
Fig.4: The hanging non-slipping ladder to reduce risks from falling from the ladder.

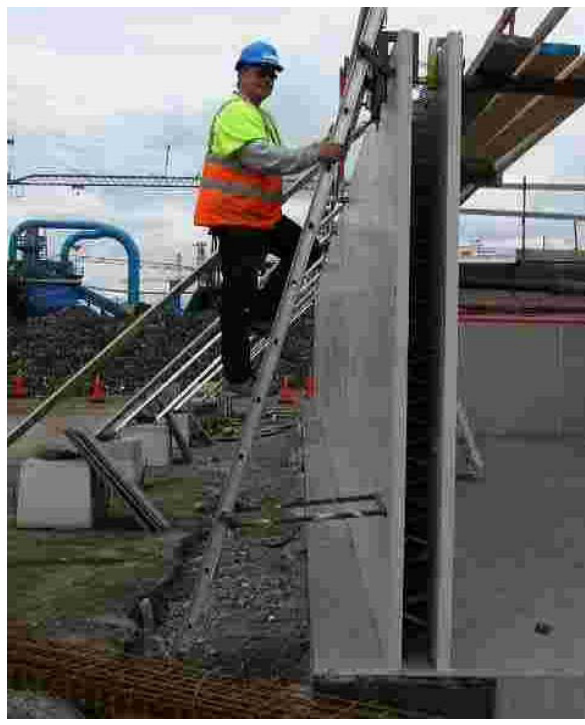

\subsection{Handbook}

Also a handbook describing the risks of handling precast concrete shells and ways to reduce those risks was developed. This was done to inform i) about risks when working with precast concrete shell elements, $i$ i) which methods and tools are available and iii) how work with precast shell elements should be carried out to avoid the risks and injuries. The handbook was intended to be used as educational material so that all who work with precast shells can obtain the relevant information of the risks and how they can be avoided. The whole chain of actions needed from placing the shells to casting are described. It is written in an easy-to- read style and has many illustrations.

\subsection{Evaluation of prototypes}

Basic safety tests and calculations of structural strength were carried out before the prototypes were tested at several construction sites. One of the safety tests resulted in terminating the development of one of the suggestions as it gave rise to a new and serious injury risk. The prototypes were tested and evaluated by mainly five construction workers and these evaluations were used in the iterative process of refining each new prototype. Up to seven refined prototypes reducing one risk were evaluated.

\subsection{Implementation and evaluation of the tools and the handbook}

The evaluation showed that the new system lowered injury risks, with at least a comparable quality of work and financial benefits.

The work related personal injury risks were assessed to be reduced considerably when using the developed new tools. The work environment is improved in several ways. With the Conny-handle the squeezing risk of the hands is more or less totally removed. The risks of falling from the ladder were assessed to decrease considerably when using the hanging ladder. The accident risks and the physical strain were assessed to be lowered when using the APJ-Clamp and the work platform compared to the building a traditional scaffold, and it is further improved if the hanging ladder is used during the assembly of the platform. The handbook was evaluated as important for spreading information of the risks and how they can be reduced.

\subsubsection{Ergonomics and usability}

The Conny-handle was considered as 'very good' or 'good' tool by all five construction workers participating in the final evaluation. This concerned the overall impression and assessment as well as different aspects of the tool such as size, weight, grip, angle, grip width and usability. The fact that it can be fastened into the belt was considered as resulting in higher usability.

The work platform where the developed $A P J$ Clamp is one part was evaluated to be easy and quick to assemble, done considerably faster than raising traditional scaffolds. The hanging ladder was evaluated as being well balanced and strongly increasing stability. The adjustability to different ladder lengths and the possibility to adjust the angle of the ladder were appreciated. The final version of the handbook was evaluated to be easy to understand, pedagogical and informative.

\subsubsection{Quality}

The evaluation of quality carried out by inspection by the APJ management showed that the new system consisting of the three new methods was at least as good as when using the traditional methods. A comment from the management was that there is always a risk of quality deficiency when there are deficiencies in safety and ergonomics. By improving ergonomics and safety, the construction worker can concentrate on the work task instead of trying to find temporary 
solutions. The anxiety about the risks of getting injured and the stress this anxiety causes is lowered according to the evaluation results.

\subsubsection{Economics}

An economic evaluation was carried out in cooperation with the manager of one of the construction companies. Effects of working with the traditional working methods were compared to working with the system consisting of the three tools and the handbook. Major gains were assessed to be less time to fulfill the tasks, especially when building work platforms, and reduced injuries which lead to less direct and indirect negative effects. The direct effects, such as sick leave costs and costs for rehabilitation are considerable once a serious injury occurs. The management of the company highlighted that the costs for the new tools is marginal in comparison to the economic risk when they are not used. As an example, preventing one falling accident in a five-year-period 'saves' around 1000 Euros per year. Among the negative indirect effects productivity losses and quality deficiencies were considered to be high.

Evaluating use of the system with the Connyhandle, the ladder and a work platform including APJ-clamps at a construction site showed that the direct costs for material and time for using the system was about 5 Euros per wall square meter, but the 'profit' from time savings by using the system systematically and repeatedly compared to solving the problems anew every time, was estimated to be several times larger.

\subsubsection{Implementation}

From the beginning of the project the aim was that the tools developed should be offered to companies who were suppliers of building material or equipment. This was considered as an important step to facilitate the dissemination of the tools on the market. However, the ladder manufacturing company that was initially considered as a partner declined this option. They considered the investment and the market for this product to be too uncertain. Regarding the APJclamp, there was co-operation with the main supplier of work platforms throughout the project, but, at the end of the project the company was not prepared to include the clamp among their products at that time. Here a factor at play may have been that the contact person within the work platform supplying company changed company and branch of industry. The company that initiated the project decided to include the production and dissemination (sale) of the Conny- handle in their company activities. They decided to offer the Conny-handle to all customers who bought concrete shells from the concrete factory within the same group of companies. They also decided to enclose the handbook in all deliveries of prefabricated concrete shells from the concrete factory.

Since the manufacturer of ladders and the supplier of work platforms declined to take on the two details for ladders and the APJ-clamp respectively, the company that initiated the project and was a driving force throughout it decided to produce these products for in-house use and also to be a supplier of them on demand to other companies. However, the company stated clearly that they were not going to put effort in marketing the products, since building equipment was not the core business of the construction company.

The system was implemented within the company that initiated the project. Information about the new system was disseminated also within the other companies active in the project, their networks, via the reference group, the information channels (newsletters etc) from SBUF and seminars. The company initiating the project was the driving force and started using the whole system. Initially there was an interest from other companies also, and especially the Conny-handle was bought in by some companies.

\subsection{Follow-up}

Five years after introducing the tools on the Swedish construction industry market anew contact was made with the company that initiated the project. The company manager was interviewed about the use and dissemination of the system. This follow up showed that the interest for and the dissemination of the system was very small among other companies in the construction industry and the company had not sold any parts of the system during the last two years. According to the manager, the Conny-handle is used by several construction workers regularly as a working tool within the company. The handbook is still included in the deliveries from the concrete factory. It is also used in work environment education of the construction workers and at the start of new projects and construction sites. In projects longer than twothree weeks the company plans the working methods and then also prescribes that the work shall be carried out using tools systematically. According to the manager, the use of the Conny-handle increases during these longer projects. In these projects also the APJclamp is used in conjunction with work-platforms. 
The use of the ladder, though, has more or less ceased.

\section{Discussion}

New injuries may also occur when developing new products, but it is difficult to identify possible risks. However, in the project some new risks were identified and eliminated. This was done partly during evaluation of ideas in phase one of the project, partly during the prototype development and testing in phase two.

The number of construction workers participating in the evaluation was, due to practical reasons, five. Therefore no statistical analysis of the evaluations was carried out. The limited number of participants also restricts the possibility to draw general conclusions.

One of the main improvements when using the developed system, besides reducing the injury risks, is that it facilitates the work and gives the possibility to work systematically using the system.

The follow-up showed that the tools have rather limited use in the Swedish construction industry. The system described in this paper is mainly, maybe even only, used by the company that initiated the project. Causes for this have not been investigated, but there may be several possible contributing factors. It is hypothesized that reasons for the low use of the system may be that $i$ ) none of the products were marketed systematically, $i$ ) that that none of the products was sold by a company specialized in providing construction equipment, iii) that a key player in a company that had that as its core business left the company and business, and $i v$ ) the company that ended up providing the products has its core business in construction, not in marketing or selling equipment.

\section{Conclusions}

In this project the aims were to identify and assess risks when working with precast concrete shells and to develop and evaluate a system consisting of tools which reduce the risks and a handbook of how to handle the shells, and implement and disseminate the results.

Three serious injury risks were identified and ideas for reducing these risks were developed, as well as a system consisting of three tools and a handbook. Alternative working methods using this system were made available for the Swedish construction industry. It is concluded that the injury risks can be reduced using the new tools/methods which also meet criteria regarding ergonomics, economics and quality.

None of the products was introduced on the market by a company specialized in construction equipment. A five-year follow-up showed that the use of the developed system was very low, perhaps even nonexistent, except within the company that initiated the project. Considering the organization of the implementation of the system on the market, the low dissemination and use point in the direction of the importance of having a relevant implementation process to reach outside the sphere of those engaged in a development project of this kind.

\section{Acknowledgement}

Financial support from SBUF, the Swedish construction industry's organization for research and development is gratefully acknowledged.

\section{References}

[1] Aagard Nielsen, K. and Svensson, L. (Eds.) (2006) Action and Interactive Research Beyond practice and theory. Shaker Publishing, Maastricht, The Netherlands.

[2] Rose, L and Örtengren, R. (2000) Personal injury risk management in companies. Proceedings of the 18th ESReDA seminar, Karlstad, 209-222, Sweden.

[3] Andersson, E R (1988) The use of system groups in product development. An experiment from the perspective of ergonomics. Stockholm. Doctorial Thesis, KTH, Trita-AAV, 0280-7521.

[4] Bohgard, M., Karlsson, S., Lovén, E., Mikaelsson, L.-Å., Mårtensson, L., Osvalder, A.-L., Rose, L., \& Ulfvengren, P. (Eds) (2009) Work and technology on human terms. Prevent.(Work environment in association with the Confederation of Swedish Enterprise, LO \& PTK). ISBN 978-91-7365-058-8, Stockholm, Sweden.

[5] Borg, G, Hassmen, P \& Lagerström, M (1987) Perceived exertion related to heartrate and blood lactate during arm and leg exercise. Eur J Appl Physiol Occup Physiol 1987; 56(6):679-685.

[6] Kuorinka, I, et al. (1987) Standardised Nordic questionnaires for the analysis of musculo-skeletal symptoms. Applied Ergonomics, 18:233-237.

[7] Stålbyggnadsinstitutet och Elementmontageföreningen (unknown publishing year, probably around 1997) (In Swedish) Bra arbetsmiljö vid stål- och betongelement-montering. Handbok i Stålbyggnadssinstitutets skriftserie "Publikationer från Stålbyggnadssinstitutet". Nr 153

[8] Special database analysis carried out by the Statistics Department at the Swedish Work Environment Authority.

[9] Samuelsson, B. \& Lundholm, L. (2001) (In Swedish) Arbetsskador inom byggindustrin 2000. Rapport BCA 2001:1, Byggindustrins Centrala Arbetsmiljöråd. Stockholm, Sweden. 